\title{
Evolved adaptation to low ultraviolet radiation may be the main cause of malignant melanoma independent of high ultraviolet radiation exposure
}

\section{Wenpeng You}

The University of Adelaide Adelaide Medical School

\section{Renata Jolanta Henneberg}

The University of Adelaide Adelaide Medical School

\section{Brendon Coventry}

The University of Adelaide Adelaide Medical School

Maciej Henneberg ( $\square$ maciej.henneberg@adelaide.edu.au )

University of Adelaide https://orcid.org/0000-0003-1941-2286

Research article

Keywords:

Posted Date: May 26th, 2020

DOI: https://doi.org/10.21203/rs.3.rs-28249/v1

License: (c) (i) This work is licensed under a Creative Commons Attribution 4.0 International License. Read Full License 


\section{Abstract}

Objective:

The low melanin production (depigmentation) evolved from low ultraviolet radiation may be the principal determinant of malignant melanoma of skin (C43).

Design:

Country-specific estimates of C43 incidence, daily UVR exposure, skin colour (EEL), socioeconomic status (GDP PPP), magnitude of reduced natural selection $\left(\mathrm{l}_{\mathrm{bs}}\right)$, ageing, urbanization, percentage of European descendants (Eu\%), and depigmentation measured by blonde hair colour, were subjected to statistical analyses. Data were derived from WHO, United Nations, World Bank databases and the literature.

Setting:

Ecological analysis

Participants:

182 individual countries.

Main outcome measures:

Parametric and non-parametric correlations, partial correlation analyses keeping confounders statistically constant, multivariate regressions and analyses of variance.

Results:

Worldwide, UVR exposure was in negative correlation with C43 ("rho" $=-0.515, p<0.001$ ). This relationship remained significant and negative in parametric partial correlation $(r=-0.513, p<0.001)$ when GDP PPP, $I_{b s}$, ageing and urbanization were statistically kept constant.

In stepwise linear regression analysis, UVR was the variable having greatest negative influence on C43 incidence $\left(R^{2}=0.301\right)$.

Worldwide, C43 incidence was in strong correlation with Eu\% $(r=0.711, p<0.001)$. The inverse relationships between C43 and UVR exposure $(r=-0.498, r<0.001)$ and Eu\% $(r=0.477, p<0.001)$ remained significant in partial correlation analysis.

When C43 incidence rate was standardized on Eu\% it did not correlate at all with UVR ("rho" $=0.004$, $p=0.967, n=127)$. The country-specific depigmentation level strongly correlated with C43 incidence $(r=$ $0.705, p<0.001, n=48$ ). Partial correlation analysis revealed that C43 correlated to depigmentation significantly $(r=0.315, p<0.01)$. However, UVR showed almost nil correlation with $\mathrm{C} 43$ when 
depigmentation, together with the other four potential confounders was included as the controlled variable.

Conclusions:

C43 incidence may not be attributable to UVR exposure. Low melanin production, genetically determined, that has adaptively evolved over generations represents an ultimate risk factor for $\mathrm{C} 43$.

\section{Introduction}

Malignant melanoma of the skin [1] (WHO ICD: C43) is a malignancy of pigment-producing cells (melanocytes) which are primarily located in the skin [2]. It represents a significant and growing public health burden worldwide. Globally, the C43 incidence rate has been increasing over past decades [3]. Worldwide, in 2012, the incidence rate of C43 reached 3.0 per 100,000 and, globally, an estimated 232,130 people developed $\mathrm{C} 43[4,5]$. Much effort has been made to investigate to what extent changes in behaviour, in the environment, or in early detection are involved, but the mechanism of the increasing incidence is still not well understood [3].

It has been constantly reported that high $\mathrm{C} 43$ incidence has occurred in people of European descents in last decades [5-9]. It is estimated that the annual increase in incidence rate of C43 for European-derived populations remains much higher than for all other populations $[5,10]$. Therefore, European phenotypes, such as blond hair, light-coloured eyes, fair skin, sun-sensitive skin, more naevi (moles) [11] and freckles [12-15] have been considered as risk factors for C43.

Extensive studies have presumptively linked $\mathrm{C} 43$ risks to sunlight exposure-related behaviours, such as strong sun exposure in childhood [16, 17], sunburn episodes [18, 19], solarium use [20], and outdoor work [21]. Although the conclusions are largely associative and circumstantial, high UVR exposure has been commonly accepted as the primary risk factor for C43.

It has been widely advised and accepted that exposure to intense UVR levels causes damage to the DNA of melanocytes, which constitutes a major contributor for developing C43 [22-28]. However, although this theory appears plausible, it poorly explains the true epidemiology of $\mathrm{C} 43$ worldwide and the regional variations. For example, UVR in the Europe region of World Health Organization (WHO) is significantly lower than in other regions [29], but its C43 incidence rate is significantly higher than other WHO regions [30]. These are detailed in the results section.

C43 prevention campaigns have advocated sunscreen use to reduce the C43 risk [31]. Contrary to the campaign aims, some epidemiological studies have showed that sun-blocking substances, such as sunscreen lotion do not protect against C43 development [32-34]. Surprisingly, studies have reported that individuals regularly applying sun block could have a higher risk of C43 than non-users [33, 35-37]. Therefore, the controversial role of sun-blocking products in protecting against and promoting C43 development remain confusing and intriguing for professionals and lay-people [3, 33]. 
Before high UVR exposure is unanimously accepted as the risk factor for $\mathrm{C} 43$, researchers have started to debate whether intermittent [38] or chronic [39] sun exposure should be considered as the risks of C43. Several studies may make the debate pointless because they have revealed that C43 can develop in skin areas with little or no UVR exposure (i.e. mouth, soles of feet, palms of hands, mucosal sites, buttock and genital areas) $[40,41]$. Moreover, a recent study published in Nature even revealed the whole-genome of some C43 subtypes which could occur without sun exposure [41].

Regardless of rare early C43 onset in young people with fair pigmentation [42], ageing is a wellestablished risk factor, which may be partially attributable to more sun exposure $[12,16,43]$ as the sun exposure is cumulative over lifetime.

From an evolutionary perspective, it has been known that human adaptation to low UVR exposure in Northern Europe over many generations resulted in decreased melanin production, most likely to permit sufficient vitamin D production in the skin in these environments [44]. During this micro-evolutionary process, recessive mutations/ genes disabling normal melanin production for skin, hair and eye colouration were accumulated. This process may also lead to fluctuation of folate and folic acid in human blood [45-47].

We advance the hypothesis that recessive mutations/genes arising during the micro-evolutionary process leading to severely reduced ability to produce melanin, may easily undergo somatic mutations resulting in C43 development. This hypothesis was tested using population-level data on human pigmentation and C43 incidence obtained from international data-collection organizations which were then adjusted for ambient UVR exposure and other variables.

\section{Materials And Methods}

\section{Data Sources}

The country-specific data published by the agencies of the United Nations were downloaded for this ecological study.

1. The GLOBOCAN 2012 estimate of country specific Melanoma of the skin (WHO C43) incidence rate in both sexes [30]

GLOBOCAN provides contemporary population level estimates by cancer site and sex [48]. This project is conducted by the World Health Organization (WHO) cancer research agency, the International Agency for Research on Cancer (IARC).

As per the International Statistical Classification of Diseases and Related Health Problems (10th Revision (ICD-10)-2015-WHO Version for 2015), IARC clustered 10 types of malignant neoplasms of skin as the malignant melanoma of skin which is coded as C43. 
C43 incidence rate is expressed as the number of persons who were diagnosed with C43 in 2012 per 100,000 population. The C43 incidence was reported as both a crude rate and an age standardised rate at world level. In order to improve the comparability of data between the countries, the age-standardized incidence rates were selected.

2. Country-specific skin reflectance (armpit) extracted from the previous publication [49]

Skin colour has been postulated as the risk factor for $\mathrm{C} 43$ for several decades [50-52]. Skin colour can be quantified as the reflectance rate of white light from the skin minimally exposed to UV radiation (in the armpit). Data on skin reflectance of various populations worldwide were previously studied and published $[45,46,53,54]$. We extracted the country-specific skin reflectance data relevant for each country from previous publications using the same file as analysed in Brace et al. [49].

3. The WHO Global Health Observatory (GHO) data on the average daily ambient ultraviolet radiation (UVR) level (in $\mathrm{J} / \mathrm{m}^{2}$ ) and life expectancy at age 60-years [29]

The country-specific UVR estimate was calculated by the WHO from the satellite data or a proxy such as latitudinal position by assuming a population-level exposure represented by yearly ambient erythemally weighted UVR [29]. UVR has been backdated by approximately 10 years (1997-2003) to reflect long exposure duration with delayed presentation of C43.

We hypothesized that micro-evolutionary adaptation to low-level UVR may be a determining factor of melanoma worldwide. Therefore, the variable UVR is interchanged as "low UVR" in order to improve the reading fluency of this paper.

Ageing has been included as a potential confounder in this study as it has been linked to C43 risk in a number of publications $[12,16,43]$. We indexed ageing at the population level with the life expectancy at age 60 in 2010, which reflects the overall mortality after the age of 60-years.

4. The World Bank published data on per-capita GDP PPP and urbanization [55]

Socio-economic level has been associated with C43 risk [48, 56]. We chose per capita GDP purchasing power rate (GDP PPP in 2012 international \$) because it takes into account the relative cost of local goods, services and inflation rates of the country.

Urbanization has been postulated as a major $\mathrm{C} 43$ predictor [57] because it represents the major demographic shift entailing lifestyle changes [58-60]. Urbanization is expressed with the country-specific percentage of total population living in urban areas in 2012.

5. Country-specific magnitude of C43 gene accumulation downloaded from previous publication [61]

Natural selection, as one of the key mechanisms of evolution, differentiates individuals' reproductive success (combination of mortality and fertility) depending on their genetic endowment. The Biological 
State Index $\left(I_{b s}\right)$ has been constructed to measure the opportunity for natural selection through differential mortality at the population level. The $\mathrm{I}_{\mathrm{bs}}$ calculation combines life table function $\mathrm{d}_{\mathrm{x}}$ (number of deaths at age $\mathrm{x}$ ) with the age-specific completed relative fertility rate $\mathrm{s}_{\mathrm{x}}$ (fraction of total fertility to a woman up to age $x): I_{b s}=1-\sum d_{x} s_{x}$. More details concerning the calculation and interpretation of this index can be found in previous publications [61-66].

Due to changing mutation/ selection balance in a population, the Biological State Index $\left(I_{b s}\right)$ can be considered as the index of country-specific magnitude of C43 gene accumulation $[63,67]$.

The country-specific $\mathrm{I}_{\mathrm{bs}}$ was downloaded from the previous publication [61]. It has been postulated that reduced natural selection (measured by increased $\mathrm{l}_{\mathrm{bs}}$ ) may have allowed accumulation of deleterious genes of non-communicable diseases such as cancers, including C43 [63], type 1 diabetes [64] and obesity $[61,68]$ at the population level.

6. The $\mathrm{C} 43$ incidence rate varies between geographical areas with the highest rates in Europe $[30,48,69]$ and in countries with greatest proportion of European descendants $[5,10,70-72]$. Therefore, we prepared the following two further variables concerning populations of European origin/ descendants.

1) Country-specific percentage of European descendants (Europeans \% hereinafter) was collected from the EuroStat for European countries [73], and government and non-EU government documents for the rest of the countries with European descendants.

2) The country grouping of the WHO Europe Region was singled out for analysing the correlation between UVR and C43. We also obtained the country-specific percentage of population with light hair [74] as the measurement of the magnitude of depigmentation (depigmentation level hereafter).

All the potential confounding variables (GDP PPP, $\mathrm{l}_{\mathrm{bs}}$, ageing and urbanization) and independent variables (Skin reflectance, UVR, Europeans \% and depigmentation level) were matched with the dependent variable, country-specific $\mathrm{C} 43$ incidence rate. We obtained a set of data consisting of 182 countries for our analysis. Each country was treated as an individual subject in this study. The number of countries for each individual variable included in the dataset may be different because not all the countries had uniformly available variables due to various reasons. All the data were extracted and saved in Microsoft Excel® for analysis.

\section{Data analysis}

Our data analysis proceeded in six steps to examine the worldwide correlation between UVR exposure and C43 incidence:

1. Scatter plots were produced with the cross-country raw data (not transformed) in Microsoft Excel ${ }^{\circledR}$ to explore and visualize the strength, shape and direction of correlation between UVR exposure and C43 incidence worldwide. Points representing Australia and New Zealand appear to be the outliers. However, 
we did not remove these two datum points as the major outliers because they represent the truth that Australia and New Zealand have the highest C43 incidence rates although their UVR levels are not the highest as per the previous publications $[5,10,75]$.

Scatter plots were also conducted to explore the relationships between C43 incidence and Europeans \% worldwide, country-specific UVR within WHO-Europe and depigmentation level within European area respectively.

2. Nonparametric correlation analysis (Spearman's $\rho$ ) was conducted to evaluate the worldwide direction and strength of the correlation between $\mathrm{C} 43$ and each independent and potentially confounding variable.

3. Partial correlation of Pearson's moment-product approach on log-transformed data was conducted to explore the worldwide correlation between $\mathrm{C} 43$ and UVR and skin reflectance respectively when we controlled for the potential confounding variables (GDP PPP, $\mathrm{I}_{\mathrm{bs}}$, ageing and urbanization).

4. Standard multiple linear regression (Stepwise) was conducted on log-transformed variables to select the variables which had the greatest influence on C43 incidence when UVR, I $I_{b s}$, ageing, GDP PPP and Urbanization were entered as the independent variables.

Considering that $\mathrm{C} 43$ has been constantly associated with people of European origin, we replaced UVR with the other two variables, "WHO EU Region" and "Europeans \%", respectively and repeated the above analyses (Step 2-4). In these two subsequent analyses, we did not analyse the relationship between the variable of skin reflectance and C43 due to the very limited number of countries with available data in each data set.

Additionally, when we conducted the partial correlation within the dataset of "WHO EU Region", we alternated depigmentation and UVR as the control variable together with the other confounding variables (GDP PPP, $\mathrm{I}_{\mathrm{bs}}$, ageing and urbanization) to explore whether UVR and depigmentation were correlated with C43 independent of each other. Similarly, when we conducted the partial correlation with the dataset of "Europeans \%", we alternated Europeans \% and UVR as the control variable together with the other confounding variables (GDP PPP, $\mathrm{I}_{\mathrm{bs}}$, ageing and urbanization) to explore whether UVR and EU\% correlated with $\mathrm{C} 43$ independent of each other.

5. Analysis of variance (ANOVA) was conducted to detect the significant differences between the six WHO regions among the means of C43 incidence rate, and "Residual of C43 standardised on UVR" [76]. Further post-hoc (Bonferroni) testing was performed to identify the source (pairs) of significant differences.

6. European population (WHO European Region) has the significantly higher incidence of $\mathrm{C} 43[5,10,70$, 71], but significantly lower UVR than in all the other WHO regions. To examine if, statistically, they could explain each other in terms of their worldwide relationships with C43 incidence, we used the analysis of residuals, because $\mathrm{C} 43$ incidence is curvilinearly related to UVR and Europeans \%. We have calculated the best fitting regression line of $\mathrm{C} 43$ to each of the two variables and then for each country predicted 
incidence of C43 using that regression. Residuals were calculated as differences between predicted C43 incidence and its actual incidence. These residuals were correlated with other variables in Spearman rho analysis. They were also correlated with one another as well.

The best fitting equations, $y=-7.902 \ln (x)+68.305\left(R^{2}=0.3629\right)$ and $y=-7.902 \ln (x)+68.305\left(R^{2}=0.3629\right)$ were applied for the calculations of residuals of C43 incidence standardized on Europeans \% and UVR respectively.

Scatter plots, ANOVA and post hoc Bonferroni tests were conducted with the raw data. Nonparametric correlation, partial correlation of Pearson's moment-product and multiple linear regression analysis (stepwise) were conducted with SPSS v. 25 on the log transformed variables. The significance was kept at the 0.05 level, but 0.01 and 0.001 levels were also reported. Standard multiple linear regression analysis criteria were set at probability of $F$ to enter $\leq 0.05$ and probability of $F$ to remove $\geq 0.10$.

Patient and Public Involvement

This study does not involve any human participants or animals.

\section{Results}

Worldwide, the relationship identified in the scatterplots between UVR and melanoma was noted to be logarithmic with a relatively strong, but negative correlation $(r=-0.6024, p<0.001, n=171$, Fig. 1$)$. This may indicate that people living in low solar ultraviolet radiation exposure environments have higher $\mathrm{C} 43$ incidence risk.

Worldwide, UVR exposure was in significant and negative correlation with C43 in non-parametric correlation analysis $(r=-0.515, p<0.001$, Table $<$ link rid="tb1" $>1</$ link $>-1)$. This relationship remained significant and negative in partial correlation $(r=-0.513, p<0.001)$ when GDP PPP, $I_{b s}$, ageing and urbanization were statistically kept constant (Table 1-2).

However, skin reflectance correlated positively with C43 at a marginally significant level $(r=0.325, p=$ $0.057, \mathrm{n}=35$, Table $<$ link rid="tb1">1</link $>-1$ ). The correlation between skin reflectance and C43 became weak $(r=0.153, r=0.505, d f=19)$ when GDP PPP, $I_{b s}$, ageing and urbanization were statistically kept constant (Table 1-2).

When UVR, GDP PPP, $I_{b s}$, ageing and urbanization were included as the predictor variables in stepwise linear regression analysis, UVR was selected as the variable having greatest influence on C43 incidence rate $\left(R^{2}=0.301\right.$, Table $\left.1-3\right)$.

The ANOVA with post hoc Bonferroni procedure revealed that WHO EU Region had the highest mean C43 incidence rate $(7.53 / 1000)$ which was, statistically, significantly higher than in any other WHO region. However, WHO EU Region having the highest incidence of C43 has the significantly lowest mean of UVR 
$\left(2189 \mathrm{~J} / \mathrm{m}^{2}\right)$ amongst all the six regions. Besides mean C43 incidence in WHO EU Region differing significantly from those in other regions, there were no significant differences between other regions (Table 2).

Average residuals of "C43 standardised on UVR" in different WHO regions do not differ between various WHO regions (Table 2). It may suggest that, without contributing effects of low UVR, the total contribution of all the other $\mathrm{C} 43$ risk factors may not be sufficient for the mean difference between WHO EU and other WHO Regions to reach a level of significance. This seems to indicate that without negative statistical effect of UVR on melanoma incidence (by calculating residuals), the Europeans would have the same C34 incidence as people from other regions.

Worldwide, the relationship identified in the scatterplots between Europeans $\%$ and melanoma was noted to be linear with a relatively strong, but negative correlation $(r=-0.6123, p<0.001, n=135$, Fig. 2$)$.

Table $3-1$ showed that C43 incidence was in negative strong correlation with UVR exposure $(r=-0.699, r$ $<0.001)$, and in strong and positive correlation with Europeans $\%(r=0.711, p<0.001)$. These relationships between C43 and UVR exposure $(r=-0.498, r<0.001)$ and Europeans \% $(r=0.477, p<0.001)$ still remained significant in partial correlation analysis when GDP PPP, $\mathrm{I}_{\mathrm{bs}}$, ageing and Urbanization were statistically kept constant (Table $3-2)$.

Stepwise multiple linear regression analysis, including $\mathrm{C} 43$ incidence rate as the dependent variable and Europeans \%, UVR, GDP PPP, $\mathrm{I}_{\mathrm{bs}}$, ageing and Urbanization as the independent variables, selected UVR as the variable $(\beta=-0.552)$ having the greatest but negative influence on $C 43$ incidence with $R^{2}=0.299$, while Europeans \% was placed second increasing $R^{2}$ to 0.336 (Table $<$ link rid="tb3">3</link $>-3$ ).

Worldwide, the residual from C43 incidence rate standardized on Europeans \% did not correlate at all UVR in Spearman's rho analysis $(r=0.004, p=0.967, n=127)$. Neither did the residual from C43 incidence rate standardized on UVR correlate with Europeans \% in Spearman's rho analysis $(r=-0.030, p=0.735, n=127)$. However, the residues standardized on UVR and Europeans showed significantly strong correlation with each other $(r=0.753, p<0.001, n=127)$. This may suggest that, statistically, worldwide, Europeans $\%$ and UVR depend on each other for their respective correlations with C43 incidence rate.

Figure 3 indicated that country-specific depigmentation level strongly correlated with C43 incidence in scatterplots (Power, $r=0.7051, p<0.001, n=48$ ).

Table 4 - 1 showed that $\mathrm{C} 43$ incidence was in strong positive correlation with both depigmentation $(r=$ $0.696, r<0.001$, Table $4-1)$ and strong negative correlation with UVR exposure $(r=-0.677, p<0.001$, Table $4-1)$. In partial correlation analysis these relationships between $C 43$ and depigmentation $(r=$ $0.512, r<0.001$, Table $4-2)$ and UVR exposure $(r=-0.425, p<0.001$, Table $4-2)$ remained significant when GDP PPP, $I_{b s}$, ageing and urbanization were statistically kept constant. Depigmentation still showed significant and positive correlation $(r=0.315, p<0.01$, Table $4-3)$ to C43 when UVR, together with other four potential confounders (GDP PPP, $\mathrm{I}_{\mathrm{bs}}$, ageing and urbanization), was included as the control variable. 
However, UVR showed almost nil correlation with C43 when depigmentation, together with the other four potential confounders (GDP PPP, $\mathrm{I}_{\mathrm{bs}}$, ageing and Urbanization), was included as the controlled variable (Table <link rid="tb4">4</link>-4). This indicates that, statistically, depigmentation is a significant C43 incidence rate predictor which is independent of UVR. In other words, it seems to suggest that depigmentation may contribute to C43 incidence rate without the contribution of UVR to this rate.

Within WHO EU, stepwise multiple regression analysis selected GDP PPP as the variable having the greatest influence on $\mathrm{C} 43$ incidence rate with $\mathrm{R}^{2}=0.642$, while depigmentation was placed second increasing $\mathrm{R}^{2}$ to 0.720 when depigmentation, GDP PPP, $\mathrm{I}_{\mathrm{bs}}$, ageing and urbanization were entered as the independent variables (Table 4-5). In the same model, GDP PPP was selected as the variable having the greatest influence on $\mathrm{C} 43$ with $\mathrm{R}^{2}=0.657$, while UVR was placed second increasing $\mathrm{R}^{2}$ to 0.711 (Table 45). Subsequently, when depigmentation was incorporated as an independent variable together with GDP PPP, $I_{b s}$, ageing and urbanization, GDP PPP was selected as the variable having the greatest influence on C43 with $R^{2}=0.657$, while depigmentation was placed second increasing $R^{2}$ to 0.732 . However, UVR was removed by the analysis as having no statistically significant influence on C43. This revealed that, statistically, the correlation between UVR and C43 was dependent on depigmentation, but depigmentation correlated with C43 independent of UVR.

\section{Discussion}

By examining the relationship between UVR and C43 incidence across 182 countries, our analysis suggests that:

1. Countries with low UVR exposure had high C43 incidence rates.

2. Countries with greater percentage of European descendants (Europeans \%) had higher C43 incidence rates.

3. There was negligible correlation between UVR exposure and country specific C43 incidence when percentage of European population was kept statistically constant (residue of C43 incidence standardized on country-specific Europeans \%).

4. In Europe, countries with high level of depigmentation had higher C43 incidence rate. Statistically, country-level depigmentation negatively correlated with country-specific UVR exposure in a stepwise model indicating its long-term evolutionary adaptation to low UVR.

Our results indicate that UVR may not be the primary cause of C43 worldwide. From the perspective of human evolution, it may be the magnitude of heritable depigmentation due to adaptation to low UVR exposure that may predispose to C43 worldwide irrespective of direct individual exposure to sunlight. We applied the modern evolutionary theory to interpreting how human adaptation has produced the underlying cause for $\mathrm{C} 43$ over a number of generations. 
The findings of our study contradict the common belief that high UVR exposure of individual humans is the primary or major risk factor for $\mathrm{C} 43[5,77-80]$. Biologically, the human body readily responds to changing environmental stresses, such as UVR, until they are adapted to keep themselves fit and survive. The adaptation process involves a mutation, or genetic change to make adapting traits inheritable. Vitamin $D$ is essential for maintaining strong bones and ensuring essential healthy functioning including the lungs, cardiovascular system, immune system, and brain [81]. Although UVR only constitutes approximately $10 \%$ of the total light output of the sun, it is the best natural force for producing vitamin $\mathrm{D}$. Melanin, produced in melanocytes, is able to dissipate more than $99.9 \%$ of UVR radiation absorbed by the skin [82]. More melanin in skin not only protects the skin cells, including the pigment cells - melanocytes - against UV damage, but also against destruction of folate [45-47]. If too much melanin is produced in the epidermis for absorbing UV irradiation, skin cells may be protected, but synthesis of vitamin D may be inhibited because of lack of penetration of UV into skin [83-85]. However, if there is not enough melanin produced in the skin, cells in skin would not have enough protection from UVR damage because more UVR would be able to penetrate deeper into the epidermis.

People living in areas with low UVR, would be advantaged by carrying the genes/ mutations which could alter their cell physiology for producing less melanin to allow more UVR penetration for more vitamin $D$ genesis and proper levels of folate [46]. Populations lacking those genes/ mutations favoured by natural selection for sufficient vitamin D production would be unfit, and selection pressure would favour elimination of high-melanin genes because the essential health effect of vitamin D was not sufficient. These mutations may evolve into inheritable genetic signatures of populations with low UVR exposure $[63,86]$. In people living in areas with low level of UVR exposure for generations, the amount of melanin in human skin must be balanced between allowing enough UV penetration to produce vitamin $D$ and preventing over-exposure from creating potential solar damage to skin cells [87].

Almost all laymen and professionals believe that too much exposure to UV radiation is the main determining factor for carcinogenic damage to skin cells, including melanocytes. However, our study, statistically suggests that C43 occurrence is not attributable to UVR exposure. Worldwide, the negative correlation between UVR and C43 indicates that low UVR, instead of too much UVR exposure, may be the principal risk factor for $\mathrm{C} 43$ at the population level. Europeans who live in the lowest UVR situations have the highest C43 incidence rates (Table 2, Figure 3-1). Extensive epidemiological studies in C43 and demographic statistics have focused on the European populations. We took advantage of these data for our analyses of the relationships between UVR and C43 in different models.

Within the WHO Europe Region, C43 incidence correlates positively with depigmentation while it correlates negatively with UVR exposure. The first relationship is independent of UVR exposure, but the latter is dependent on depigmentation. Further regression analyses implied that, statistically, 1) low UVR and Europeans \% explained each other for their contributing effects to C43. 2) if Europeans could live in any other WHO Region with higher UVR exposure, their C43 incidence may be at the similar level to Europe, and significantly different from people who have lived in that region for generations. Evolutionarily, low UVR has forced Europeans to depigment, and the genetically determined 
depigmentation may have made Europeans more susceptible to C43 independent of the environmental factor, UVR. The results of our study are in agreement with the finding that C43 can develop in skin areas with little or no UVR exposure [40,41]. A recent study even revealed the whole-genome landscapes of major C43 subtypes which could occur without UVR [41]. Also, a study conducted by Rampen and Fleuren postulated that C43 may not be caused by UVR, but by xenobiotic influence [88].

Large-scale primary C43 prevention programmes aiming at little UVR exposure have not yet been proven effective [32, 34, 89], or unexpectedly, exacerbated C43 initiation [33, 35-37]. This may be explained by our hypothesis that C43 may primarily be a genetic disease due to long-term adaptation to low UVR, but this process aids vitamin $\mathrm{D}$ production to maintain essential healthy functioning including the bones, lungs, cardiovascular system, immune system, and brain [81].

The other key finding in this study is that, worldwide, countries with low UVR had the trend to have high C43 incidence. This is completely opposite to the current commonly accepted belief, "high UVR, high risk for C43" which was primarily concluded from previous C43 epidemiology studies in Australia and New Zealand. As shown in Figure 1, Australia and New Zealand have the highest C43 incidence rates internationally (34.90 and 35.80 per 100,000 respectively) [48], but their UVRs (3206 and $2487 \mathrm{~J} / \mathrm{m}^{2}$ respectively) are much lower than in many countries with low C43 incidence rates [29]. This finding is not explained by the common conclusion of "high UVR, high C43".

Australians and New Zealanders are predominately European descendants, coming mostly from Northern Europe that includes Britain and Ireland. Australia and New Zealand do have somewhat higher UVR levels (3206 and $2487 \mathrm{~J} / \mathrm{m}^{2}$ respectively) than Europe $\left(2198 \mathrm{~J} / \mathrm{m}^{2}\right)$, while their C43 incidence rates (34.90/100,000 and 35.80/100,000 respectively) are very much greater than in Europe $(7.53 / 100,000)$. While the UVRs in both Australia and New Zealand are lower than the worldwide mean UVR $\left(3802 \mathrm{~J} / \mathrm{m}^{2}\right)$, their C43 rates are much higher than the worldwide rate $(3.0 / 100,000)$. Although, there has been no clinical trial showing that high UVR causes C43 [88], most people, including laymen and professionals may still have been misled to believe that high UVR is the primary risk factor for C43 in Australia and New Zealand, or even globally. We have considered several factors which may make the correlation of high UVR with high C43 apparently spurious in Australia and New Zealand:

1) Australia and New Zealand have the highest rates of skin cancer incidence in the world, almost four times the rates registered in Canada, the United Kingdom and the United States of America [30] despite their UVR exposure being below the world average. Australians and New Zealanders have learned how to minimize sun exposure, how to seek cancer screening and self-diagnose skin cancers from a young age. For instance, skin cancer has been considered as a "National Cancer" [90]. This strong awareness of skin cancer, compounded by a high level of medical service delivery, has enabled Australians and New Zealanders to be diagnosed with more $\mathrm{C} 43$ through self-diagnosis and cancer screening. These effects have increased incidence statistics. 
2) Non-melanoma skin cancers (NMSC), most of which are basal cell carcinoma (BCC) and squamous cell carcinoma (SCC), account for over $98 \%$ of total skin cancers. Patients with BCC and/or SCC may have an increased risk for developing $\mathrm{C} 43$ [91-95] and certainly have the highest possibility of early melanoma diagnosis their skin being clinically assessed multiple times during BCC and SCC treatments.

3) The 5-year survival rate in C43 is very high ( $>90 \%)$ in Australia and New Zealand, while the history of C43 has a defined chance for reoccurrence [92]. Even "cured" patients with past melanoma are subject to a higher risk of developing a further new $\mathrm{C} 43$, making $\mathrm{C} 43$ incidence even higher in these countries.

4) High levels of medical services and nutrition have substantially reduced natural selection. Almost all Australians and New Zealanders survive their full reproductive period, and they have the opportunity to pass on their $\mathrm{C} 43$ mutations/genes to the next generation. When this process repeats for 4-5 generations, the $\mathrm{C} 43$ mutations/ genes accumulate and the phenotype of C43 then becomes noticeable at the population level $[64,68]$.

5) Low fertility rates have been associated with cancer risks in both females and males [67, 96, 97]. Fertility rates in Australia and New Zealand are much lower than in many other countries. This may also partially explain the higher $\mathrm{C} 43$ rates in these two countries.

It has been reported that vitamin D may protect against the development of cancers, including C43 [98100]. Although people who lived for generations in areas with low UVR exposure produce less melanin allowing more UVR to penetrate skin for more vitamin D genesis, they still have higher risk of developing C43. There may be two reasons: 1) Mutations have occurred in the genome of the people living in low UVR area, which made them prone to develop C43. Although those people could have favourable factors, such as sufficient vitamin D production, they still have high risk of developing $\mathrm{C} 43$ because their $\mathrm{C} 43$ is a genetically determined disease. 2) Vitamin $\mathrm{D}$ alone may not be capable of attenuating or preventing $\mathrm{C} 43$ occurrence.

In our study, skin reflectance correlated with $\mathrm{C} 43(\mathrm{r}=0.325, \mathrm{p}=0.057, \mathrm{n}=35)$ at a similar level, but positively, to the negative correlation of UVR with $\mathrm{C} 43(\mathrm{r}=-0.515, \mathrm{r}<0.001, \mathrm{n}=171)$ in non-parametric analysis. However, the former correlation between armpit skin reflectance and C43 incidence lost significance and became weak $(r=0.153, r=0.505 d f=19)$ in the subsequent partial correlation. The explanations could be: 1) The smaller sample size of armpit skin reflectance. 2) Armpit skin reflectance may not be a precise measure of melanin production in the skin because great variability of skin colour in different seasons and body sites [101-103]. Pigmentation may vary $70-100 \%$ in skin [104]. Therefore, pigmentation of UVR unexposed skin, including the armpit or inside of the upper arm cannot fully represent the constitutive skin pigmentation $[50-52,104]$.

\section{Conclusion}

The "high UVR, high C43 incidence" theory does not explain C43 epidemiology regionally and globally. Our study suggests that genetic coding related to low melanin production in skin, which evolved as a 
genetic adaptive trait to low UVR exposure over generations, is the primary risk factor for C43. Since abnormalities in vitamin $\mathrm{D}$ and folate affect individuals in pre-reproductive and reproductive phases of life, while most C43 occurs later in life (mostly post-reproductive), natural selection acting through differential reproductive success could support depigmentation over a small and less reproductively meaningful risk of malignancy - to favour increased melanoma risk with progressive adaptive depigmentation.

\section{What is already known on this topic \\ Human adaptations to changing environments, such as ultraviolet radiation, result from alterations of the genetic code. The amount of melanin produced in the skin is inversely related to the ultraviolet radiation human populations were exposed to over generations.}

The wholegenome landscapes of major malignant melanoma subtypes have revealed that they could occur without sun exposure.

Reduction of skin exposure to ultraviolet radiation does not prevent incidence of malignant melanoma.

\section{What this study adds}

Statistically, populations living in the low ultraviolet radiation environments have greater risk to develop malignant melanoma than those exposed to high ultraviolet radiation.

Malignant melanoma is a genetic disease resulting from the natural selection for low melanin production genes in environments with low ultraviolet radiation exposure.

Genes for low melanin production in the normal skin may be prone to somatic mutations causing malignant melanoma.

\section{Abbreviations}

WHO

World Health Organization

ICD

International Classification of Diseases

C43

Malignant melanoma coded as C43 as per International Classification of Diseases UN

The United Nations

Ibs

Biological State Index

GDP PPP

Gross domestic product at Purchasing Power Parity

UVR

Ultraviolet radiation exposure

SES 
Socioeconomic status

BCC

basal cell carcinoma

SCC

squamous cell carcinoma

\section{Declarations}

\section{Ethics approval and consent to participate}

This study does not involve any human participants or animals. Ethical approval is not required.

\section{Data sharing}

All data for this study are publicly available from the United Agencies' websites. The purpose of using these in this study meets the terms and conditions of the relevant UN agencies. The formal permission is not required to download and analyse the data in this study. The data sources have been detailed in the "Materials and Methods".

\section{Consent for publication}

Not applicable.

\section{Funding}

There is no specific funding support to this study.

\section{Competing interests}

The authors have no competing interests to declare.

\section{Authors' contributions}

$\mathrm{MH}$ conceived the hypothesis and study design, and $\mathrm{WY}$ and $\mathrm{MH}$ collected the data and conducted the analyses. $\mathrm{WY}, \mathrm{RH}, \mathrm{BJC}$ and $\mathrm{MH}$ interpreted the data. $\mathrm{RH}, \mathrm{BJC}$ and $\mathrm{MH}$ provided inputs for $\mathrm{WY}$ to draft and revise the manuscript. All authors reviewed, edited and approved the final manuscript.

\section{Acknowledgments}

We thank Dr John Relethford for providing a large part of data on skin colour.

\section{References}

1. International Agency for Research on Cancer. Cancer. 201722 December 2017]; Available from: http://globocan.iarc.fr/Pages/cancer.aspx. 
2. National Cancer Institute. Melanoma Treatment (PDQ®) Health Professional Version (March 22, 2018).

3. Berwick M, Wiggins C. The current epidemiology of cutaneous malignant melanoma. Front Biosci. 2006;11(1):1244-54.

4. IARC-WHO. DataSource_and_methods. 2017; Available from: http://globocan.iarc.fr/Pages/DataSource_and_methods.aspx\#.

5. Stewart BW. World Cancer Report 2014. Lyon: Lyon, FRA: International Agency for Research on Cancer; 2014.

6. Azoury SC, Lange JR. Epidemiology, risk factors, prevention, and early detection of melanoma. Surgical Clinics. 2014;94(5):945-62.

7. Armstrong B, Kricker A. How much melanoma is caused by sun exposure? Melanoma research. 1993;3(6):395-401.

8. La Vecchia C, et al. Recent declines in worldwide mortality from cutaneous melanoma in youth and middle age. International journal of cancer. 1999;81(1):62-6.

9. Coleman M, et al. Melanoma of the skin. Trends in cancer incidence mortality. 1993;121(16):379401.

10. Erdei E, Torres SM. A new understanding in the epidemiology of melanoma. Expert Rev Anticancer Ther. 2010;10(11):1811-23.

11. Gandini S, et al. Meta-analysis of risk factors for cutaneous melanoma: I. Common and atypical naevi. European journal of cancer. 2005;41(1):28-44.

12. Veierød MB, et al. Sun and solarium exposure and melanoma risk: effects of age, pigmentary characteristics, and nevi. Cancer Epidemiology Prevention Biomarkers. 2010;19(1):111-20.

13. Gandini S, et al. Meta-analysis of risk factors for cutaneous melanoma: III. Family history, actinic damage and phenotypic factors. European journal of cancer. 2005;41(14):2040-59.

14. Markovic SN, et al. Malignant melanoma in the 21st century, part 1: epidemiology, risk factors, screening, prevention, and diagnosis. in Mayo Clinic Proceedings. 2007. Elsevier.

15. D'Orazio J, et al. UV radiation and the skin. Int J Mol Sci. 2013;14(6):12222-48.

16. Kricker A, et al. Ambient UV, personal sun exposure and risk of multiple primary melanomas. Cancer Causes Control. 2007;18(3):295-304.

17. Wu S, et al., Long-term ultraviolet flux, other potential risk factors, and skin cancer risk: a cohort study. Cancer Epidemiology and Prevention Biomarkers, 2014.

18. Pfahlberg A, Kölmel KF, Group GFTFS. Timing of excessive ultraviolet radiation and melanoma: epidemiology does not support the existence of a critical period of high susceptibility to solar ultraviolet radiation-induced melanoma. Br J Dermatol. 2001;144(3):471-5.

19. Kennedy $C$, et al. The influence of painful sunburns and lifetime sun exposure on the risk of actinic keratoses, seborrheic warts, melanocytic nevi, atypical nevi, and skin cancer. Journal of Investigative Dermatology. 2003;120(6):1087-93. 
20. Lazovich D, et al., Indoor tanning and risk of melanoma: a case-control study in a highly exposed population. Cancer Epidemiology and Prevention Biomarkers, 2010: p. 1055-9965. EPI-09-1249.

21. Fritschi L, Driscoll T. Cancer due to occupation in Australia. Aust N Z J Public Health. 2006;30(3):213-9.

22. Thomas NE, et al. Number of nevi and early-life ambient UV exposure are associated with BRAFmutant melanoma. Cancer Epidemiology Prevention Biomarkers. 2007;16(5):991-7.

23. Thomas NE, Berwick M, Cordeiro-Stone M. Could BRAF mutations in melanocytic lesions arise from DNA damage induced by ultraviolet radiation? Journal of Investigative Dermatology. 2006;126(8):1693-6.

24. Poynter JN, et al. BRAF and NRAS mutations in melanoma and melanocytic nevi. Melanoma research. 2006;16(4):267-73.

25. Rigel DS, Rigel EG, Rigel AC. Effects of altitude and latitude on ambient UVB radiation. J Am Acad Dermatol. 1999;40(1):114-6.

26. Aceituno-Madera P, et al. Melanoma, altitude, and UV-B radiation. Actas Dermosifiliogr. 2011;102(3):199-205.

27. Wang SQ, et al. Ultraviolet A and melanoma: a review. J Am Acad Dermatol. 2001;44(5):837-46.

28. Thomas NE. BRAF somatic mutations in malignant melanoma and melanocytic naevi. Melanoma research. 2006;16(2):97-103.

29. WHO. Global Health Observatory, the data repository. WHO. 2015 [11.26.2015]; Available from: http://www.who.int/gho/database/en/.

30. Ferlay J, et al. GLOBOCAN 2012 v1.0, Cancer Incidence and Mortality Worldwide: IARC CancerBase No. 11 [Internet]. 2013 28.05.2016]; Available from: http://globocan.iarc.fr.

31. Green AC, et al. Reduced melanoma after regular sunscreen use: randomized trial follow-up. J Clin Oncol. 2011;29(3):257-63.

32. Dennis LK, Freeman LEB, VanBeek MJ. Sunscreen use and the risk for melanoma: a quantitative review. Ann Intern Med. 2003;139(12):966-78.

33. Sober A. Sunscreens and melanoma: an on-going controversy. Melanoma Res. 2010;20:e6.

34. Bastuji-Garin S, Diepgen T. Cutaneous malignant melanoma, sun exposure, and sunscreen use: epidemiological evidence. Br J Dermatol. 2002;146(s61):24-30.

35. Xie F, et al. Analysis of association between sunscreens use and risk of malignant melanoma. Int $\mathrm{J}$ Clin Exp Med. 2015;8(2):2378.

36. Gorham ED, et al. Do sunscreens increase risk of melanoma in populations residing at higher latitudes? Ann Epidemiol. 2007;17(12):956-63.

37. Westerdahl $\mathrm{J}$, et al. Sunscreen use and malignant melanoma. International journal of cancer. 2000;87(1):145-50.

38. Cho E, et al. Risk factors and individual probabilities of melanoma for whites. Journal of clinical oncology. 2005;23(12):2669-75. 
39. Gandini S, et al. Meta-analysis of risk factors for cutaneous melanoma: II. Sun exposure. European journal of cancer. 2005;41(1):45-60.

40. Goydos JSS, Steven L. Acral Lentiginous Melanoma. Cancer Treatment and Research, 2016(167): p. 321-329.

41. Hayward NK, et al. Whole-genome landscapes of major melanoma subtypes. Nature. 2017;545(7653):175-80.

42. Bleyer WA. Cancer in older adolescents and young adults: epidemiology, diagnosis, treatment, survival, and importance of clinical trials. Pediatr Blood Cancer. 2002;38(1):1-10.

43. Lasithiotakis KG, Petrakis IE, Garbe C. Cutaneous melanoma in the elderly: epidemiology, prognosis and treatment. Melanoma research. 2010;20(3):163-70.

44. Jablonski NG, Chaplin G, Human skin pigmentation as an adaptation to UV radiation. Proceedings of the National Academy of Sciences, 2010: p. 200914628.

45. Jablonski NG, Chaplin G. The evolution of human skin coloration. Journal of human evolution. 2000;39(1):57-106.

46. Jablonski NG, Chaplin G, Human skin pigmentation as an adaptation to UV radiation. Proceedings of the National Academy of Sciences, 2010. 107(Supplement 2): p. 8962-8968.

47. Borradale DC, Kimlin MG. Folate degradation due to ultraviolet radiation: possible implications for human health and nutrition. Nutrition reviews. 2012;70(7):414-22.

48. Ferlay $\mathrm{J}$, et al. Cancer incidence and mortality worldwide: sources, methods and major patterns in GLOBOCAN 2012. Int J Cancer. 2015;136(5):E359-86.

49. Brace $C$, Henneberg M, Relethford J. Skin color as an index of timing in human evolution. in American Journal of Physical Anthropology. 1999,28. Am J Phys Anthopol Suppl.

50. Lancaster H, Nelson J. Sunlight as a cause of melanoma; a clinical survey. The Medical journal of Australia. 1957;44(14):452.

51. Evans RD, et al. Risk Factors for the Development of Malignant Melanoma-I: Review of Case-Control Studies. J Dermatol Surg Oncol. 1988;14(4):393-408.

52. Bliss JM, et al. Risk of cutaneous melanoma associated with pigmentation characteristics and freckling: Systematic overview of 10 case-control studies. International journal of cancer. 1995;62(4):367-76.

53. Relethford JH. Hemispheric difference in human skin color. American Journal of Physical Anthropology: The Official Publication of the American Association of Physical Anthropologists. 1997;104(4):449-57.

54. Diamond J. Evolutionary biology: geography and skin colour. Nature. 2005;435(7040):283.

55. The World Bank Group. World Bank Open Data. 2016 12.07.2016]; Available from: http://data.worldbank.org/.

56. Cancer Research UK. Risks and causes of melanoma. 15 Dec 201515 May 2018]; Available from: http://about-cancer.cancerresearchuk.org/about-cancer/melanoma/risks-causes. 
57. Sharp L, et al. Risk of several cancers is higher in urban areas after adjusting for socioeconomic status. Results from a two-country population-based study of 18 common cancers. J Urb Health. 2014;91(3):510-25.

58. Allender $S$, et al. Quantification of urbanization in relation to chronic diseases in developing countries: a systematic review. J Urban Health. 2008;85(6):938-51.

59. Moore M, Gould P, Keary BS. Global urbanization and impact on health. Int J Hyg Environ Health. 2003;206(4):269-78.

60. WHO. Urbanization and health. WHO 2010 2010-12-07 15:20:05 2 November 2016]; Available from: http://www.who.int/bulletin/volumes/88/4/10-010410/en/.

61. Budnik A, Henneberg M. Worldwide increase of obesity is related to the reduced opportunity for natural selection. PloS one. 2017;12(1):e0170098.

62. Stephan $\mathrm{CN}$, Henneberg M. Medicine may be reducing the human capacity to survive. Med Hypotheses. 2001;57(5):633-37.

63. You W and H. M, Cancer incidence increasing globally: The role of relaxed natural selection. Evol Appl., 2017. 00:1-13.

64. You W-P, Henneberg M. Type 1 diabetes prevalence increasing globally and regionally: the role of natural selection and life expectancy at birth. BMJ Open Diabetes Research Care. 2016;4(1):e000161.

65. Henneberg M, Piontek J. Biological state index of human groups. Przeglad Anthropologiczny. 1975;XLI:191-201.

66. Henneberg M. Reproductive possibilities and estimations of the biological dynamics of earlier human populations. J Hum Evol. 1976;5:41-8.

67. You W, Symonds I, Henneberg M. Low fertility may be a significant determinant of ovarian cancer worldwide: an ecological analysis of cross-sectional data from 182 countries. Journal of ovarian research. 2018;11(1):68.

68. You W, Henneberg M. Relaxed natural selection contributes to global obesity increase more in males than in females due to more environmental modifications in female body mass. PloS one. 2018;13(7):e0199594.

69. Project MMM. Epidemiology. 2007-2015 09 June 2018].

70. Chen ST, Geller AC, Tsao H. Update on the epidemiology of melanoma. Current dermatology reports. 2013;2(1):24-34.

71. Park SL, et al., Risk factors for malignant melanoma in white and non-white/non-African American populations: the multiethnic cohort. Cancer Prevention Research, 2012.

72. American Cancer Society I,... Key Statistics for Melanoma Skin Cancer. 201822 May 2018]; Available from: https://www.cancer.org/cancer/melanoma-skin-cancer/about/key-statistics.html.

73. European Commission eurostat,.. Statistics Explained. 201715 May 2018]; Available from: http://ec.europa.eu/eurostat/statistics-explained/index.php/Main_Page. 
74. Carleton SC. The Races of Europe. April 1939, New York: The Macmillan Company.

75. Buettner PG, MacLennan R. Geographical variation of incidence of cutaneous melanoma in Queensland. Aust J Rural Health. 2008;16(5):269-77.

76. WHO. Global Health Risks Mortality and Burden of Disease Attributable to Selected Major Risks. Geneva: Geneva: World Health Organization; 2009.

77. Kanavy HE, Gerstenblith MR. Ultraviolet radiation and melanoma. in Seminars in cutaneous medicine and surgery. 2011. Frontline Medical Communications.

78. Armstrong BK, How sun exposure causes skin cancer: an epidemiological perspective, in Prevention of skin cancer. 2004, Springer. p. 89-116.

79. Pfeifer GP, Besaratinia A. UV wavelength-dependent DNA damage and human non-melanoma and melanoma skin cancer. Photochemical photobiological sciences. 2012;11(1):90-7.

80. Mahendraraj; K, et al. Malignant Melanoma in African-Americans- A Population-Based Clinical Outcomes Study Involving 1106 African-American Patients from the Surveillance, Epidemiology, and End Result (SEER) Database (1988-2011). Medicine. 2017;96(15):e6258.

81. Yuen A, Jablonski N. Vitamin D: in the evolution of human skin colour. Medical hypotheses. 2010;74(1):39-44.

82. Meredith P, Riesz J. Radiative relaxation quantum yields for synthetic eumelanin. Photochemistry photobiology. 2004;79(2):211-6.

83. López $\mathrm{S}$, et al. The interplay between natural selection and susceptibility to melanoma on allele $374 \mathrm{~F}$ of SLC45A2 gene in a South European population. PloS one. 2014;9(8):e104367.

84. Bell $\mathrm{NH}$, et al. Evidence for alteration of the vitamin D-endocrine system in obese subjects. J Clin Investig. 1985;76(1):370-3.

85. Kennel KA, Drake MT, Hurley DL. Vitamin D deficiency in adults: when to test and how to treat. in Mayo Clinic Proceedings. 2010. Elsevier.

86. Sturm RA, Duffy DL. Human pigmentation genes under environmental selection. Genome biology. 2012;13(9):248.

87. Greaves $\mathrm{M}$, Was skin cancer a selective force for black pigmentation in early hominin evolution? Proc. R. Soc. B, 2014. 281(1781): p. 20132955.

88. Rampen $\mathrm{FH}$, Fleuren E. Melanoma of the skin is not caused by ultraviolet radiation but by a chemical xenobiotic. Medical hypotheses. 1987;22(4):341-6.

89. Bataille V, de Vries E, Melanoma-Part 1: epidemiology, risk factors, and prevention. BMJ (Clinical research ed.), 2008. 337.

90. Australian Government Department of Health. Australian Government Response to House of Representatives Standing Committee on Health Report - Skin Cancer in Australia: Our National Cancer. Australian Government Department of Health: Online: Australian Government Department of Health, Editor.; 2014. 
91. Cho HG, et al., Frequent basal cell cancer development is a clinical marker for inherited cancer susceptibility. JCl insight, 2018. 3(15).

92. American Cancer Society. Risk Factors for Melanoma Skin Cancer. 2016 27/01/2019]; Available from: https://www.cancer.org/cancer/melanoma-skin-cancer/causes-risks-prevention/riskfactors.html.

93. Wassberg C, et al. Second primary cancers in patients with squamous cell carcinoma of the skin: a population-based study in Sweden. International journal of cancer. 1999;80(4):511-5.

94. Milán T, et al. Subsequent primary cancers after basal-cell carcinoma: a nationwide study in Finland from 1953 to 1995. International journal of cancer. 2000;87(2):283-8.

95. Frisch $\mathrm{M}$, et al. Risk for subsequent cancer after diagnosis of basal-cell carcinoma: a populationbased, epidemiologic study. Ann Intern Med. 1996;125(10):815-21.

96. You W, et al. Decreasing Birth Rate Determining Worldwide Incidence and Regional Variation of Female Breast Cancer. Advances in Breast Cancer Research. 2018;07(01):1-14.

97. You W, et al. Greater family size is associated with less cancer risk: an ecological analysis of 178 countries. BMC Cancer. 2018;18(1):924.

98. Field S, Newton-Bishop JA. Melanoma and vitamin D. Molecular oncology. 2011;5(2):197-214.

99. Osborne J, Hutchinson P. Vitamin D and systemic cancer: is this relevant to malignant melanoma? $\mathrm{Br}$ J Dermatol. 2002;147(2):197-213.

100. Grant WB. An ecological study of cancer incidence and mortality rates in France with respect to latitude, an index for vitamin D production. Dermato-endocrinology. 2010;2(2):62-7.

101. GREEN A, Martin NG. Measurement and perception of skin colour in a skin cancer survey. $\mathrm{Br} \mathrm{J}$ Dermatol. 1990;123(1):77-84.

102. Wulf H, Lock-Andersen J, Measurement of constitutive skin phototypes, in Skin cancer and UV radiation. 1997, Springer. p. 169-180.

103. Lock-Andersen J, Drzewiecki KT, Wulf HC, Eye and Hair Colour, Skin Type, and Constitutive Skin Pigmentation as Risk Factors for Basal Cell Carcinoma and Cutaneous Malignant Melanoma. ACTA DERMATOVENEREOLOGICA-STOCKHOLM-, 1999. 79: p. 74-80.

104. Lock-Andersen J, Wulf H. Seasonal variation of skin pigmentation. Acta dermato-venereologica. 1997;77(3):219-21.

105. Levin KA. Study design VI-Ecological studies. Evid-Based Dent. 2006;7(4):108.

106. Morgenstern H. Ecologic studies in epidemiology: concepts, principles, and methods. Annu Rev Public Health. 1995;16(1):61-81.

107. You W, Henneberg M. Meat in modern diet, just as bad as sugar, correlates with worldwide obesity: an ecological analysis. Journal of Nutrition Food Sciences. 2016;6:517.

108. You W, Henneberg M. Meat consumption providing a surplus energy in modern diet contributes to obesity prevalence: an ecological analysis. BMC Nutrition, 2016. 2(1). 


\section{Tables}

Table 1 Worldwide relationships between melanoma (C43) incidence and UVR exposure in nonparametric (Spearman "rho"), partial correlations and Stepwise multiple linear regression analyses

\begin{tabular}{|c|c|c|c|c|c|c|c|}
\hline & \multirow{2}{*}{\multicolumn{2}{|c|}{$\begin{array}{c}\text { Table 1-1: } \\
\text { Nonparametric }\end{array}$}} & \multirow{2}{*}{\multicolumn{2}{|c|}{$\begin{array}{l}\text { Table 1-2: } \\
\text { artial Correlation }\end{array}$}} & \multirow{2}{*}{\multicolumn{3}{|c|}{$\begin{array}{c}\text { Table 1-3: } \\
\text { Stepwise multiple linear regression }\end{array}$}} \\
\hline & & & & & & & \\
\hline & $\mathrm{r}$ & $\mathrm{n}$ & $\mathrm{r}$ & $\mathrm{df}$ & Rank & k Independent Variables & Adjusted $\mathrm{R}^{2}$ \\
\hline UVR exposure (Negative) & $-0.515^{* * *}$ & 171 & $-0.513^{* * *}$ & 163 & 1 & UVR Exposure (Negative) & 0.301 \\
\hline Skin reflectance & $0.325^{\# \#}$ & 35 & 0.153 & 19 & 2 & $\mathrm{I}_{\mathrm{bs}}$ & 0.321 \\
\hline GDP PPP & $0.383^{* * *}$ & 172 & - & - & 3 & Ageing & 0.363 \\
\hline $\mathrm{I}_{\mathrm{bs}}$ & $0.456^{* * *}$ & 172 & - & - & 4 & GDP PPP & Insignificant \\
\hline Ageing & $0.415^{* * *}$ & 174 & - & - & 5 & Urbanization & Insignificant \\
\hline Urbanization & $0.354^{* * *}$ & 178 & - & - & & & \\
\hline
\end{tabular}

Significance level of correlation: $* \mathrm{p}<0.05, * * \mathrm{p}<0.01, * * * \mathrm{p}<0.001$

\# Keeping intake of GDP PPP, $\mathrm{I}_{\mathrm{bs}}$, life e (60) and urbanization constant.

\#\# $\mathrm{p}=0.057$, marginally significant at the level of $\mathrm{p}<0.05$

Data sources: Melanoma of skin incidence rate from the International Agency for Research on Cancer, WHO agent in cancer research; UVR, expressed as the average daily ambient ultraviolet radiation level (in $\mathrm{J} / \mathrm{m}^{2}$ ) \& ageing, indexed by life $\mathrm{e}_{60}$ from the World Health Organization; Skin reflectance from previous publication (Brace, Henneberg \& Relethford, 1999); GDP PPP \& Urbanization from the World Bank; $\mathrm{I}_{\mathrm{bs}}$ from the previous publication (Budnik \& Henneberg 2017).

Table 2 Comparisons of mean differences of melanoma (C43), UVR and Residuals of C43 standardised on UVR between WHO regionsrespectively 


\begin{tabular}{|c|c|c|c|c|c|c|}
\hline \multicolumn{2}{|c|}{$\begin{array}{l}\text { C43 incidence rate, } \\
\quad \text { Std Dev }=5.51\end{array}$} & \multicolumn{2}{|c|}{$\begin{array}{l}\text { UVR exposure, } \\
\text { Std Dev=1465.29 }\end{array}$} & \multicolumn{2}{|c|}{$\begin{array}{l}\text { Residual of C } 43 \text { standardised on UVR, } \\
\text { Std Dev }=4.50\end{array}$} & \multirow{4}{*}{$\begin{array}{l}\text { WHO } \\
\text { Region } \\
\text { J }\end{array}$} \\
\hline I (Region) & Mean & I (Region) & Mean & I (Region) & Mean & \\
\hline $\mathrm{n}$ & Difference (I-J)/Std & $\mathrm{n}$ & Difference (I-J)/Std & $\mathrm{n}$ & Difference (I-J)/Std & \\
\hline Mean & Dev* & Mean & Dev & Mean & Dev & \\
\hline $\mathrm{AF}$ & -0.16 & $\mathrm{AF}$ & 0.39 & $\mathrm{AF}$ & 0.05 & $\mathrm{AM}$ \\
\hline $\mathrm{n}=45$ & 0.13 & $n=43$ & $0.50^{*}$ & $\mathrm{n}=44$ & 0.46 & EM \\
\hline \multirow[t]{3}{*}{ Mean=1.13 } & $-1.16^{* * *}$ & Mean $=5182$ & $2.04^{* * *}$ & Mean $=-0.15$ & 0.14 & EU \\
\hline & 0.13 & & 0.13 & & 0.32 & SEA \\
\hline & -0.39 & & $0.76^{* * * *}$ & & 0.11 & WP \\
\hline AM & 0.16 & $\mathrm{AM}$ & -0.39 & $\mathrm{AM}$ & -0.05 & $\mathrm{AF}$ \\
\hline $\mathrm{n}=32$ & 0.28 & $\mathrm{n}=30$ & 0.10 & $\mathrm{n}=29$ & 0.41 & EM \\
\hline \multirow[t]{3}{*}{ Mean=2.01 } & $-1.00^{* * *}$ & Mean $=4607$ & $1.64^{* * *}$ & Mean=-0.12 & 0.09 & EU \\
\hline & 0.29 & & -0.27 & & 0.27 & SEA \\
\hline & -0.23 & & 0.37 & & 0.06 & WP \\
\hline EM & -0.13 & $\mathrm{EM}$ & $-0.50^{*}$ & EM & -0.46 & $\mathrm{AF}$ \\
\hline $\mathrm{n}=22$ & -0.28 & $\mathrm{n}=21$ & -0.10 & $\mathrm{n}=18$ & -0.41 & $\mathrm{AM}$ \\
\hline \multirow[t]{3}{*}{ Mean $=0.44$} & $-1.29^{* * *}$ & Mean $=4457$ & $1.54^{* * *}$ & Mean $=-1.18$ & -0.32 & $\mathrm{EU}$ \\
\hline & 0.00 & & -0.37 & & -0.13 & SEA \\
\hline & $\begin{array}{r}-0.52 \\
-0.0 .\end{array}$ & & 0.26 & & $\begin{array}{l}-0.34 \\
-0.34\end{array}$ & WP \\
\hline EU & $1.16^{* * *}$ & $\mathrm{EU}$ & $-2.04^{* * *}$ & EU & -0.14 & $\mathrm{AF}$ \\
\hline $\mathrm{n}=50$ & $1.00^{* * *}$ & $\mathrm{n}=48$ & $-1.64^{* * *}$ & $\mathrm{n}=50$ & -0.09 & $\mathrm{AM}$ \\
\hline \multirow[t]{3}{*}{ Mean=7.53 } & $1.29^{* * *}$ & Mean $=2198$ & $-1.54^{* * *}$ & Mean $=2.00$ & 0.32 & EM \\
\hline & $1.29^{* * *}$ & & $-1.91^{* * *}$ & & 0.18 & SEA \\
\hline & $0.77^{* *}$ & & $-1.28^{* * *}$ & & -0.03 & WP \\
\hline SEA & -0.13 & SEA & -0.13 & SEA & -0.32 & $\mathrm{AF}$ \\
\hline $\mathrm{n}=11$ & -0.29 & $\mathrm{n}=11$ & 0.27 & $\mathrm{n}=10$ & -0.27 & $\mathrm{AM}$ \\
\hline \multirow[t]{3}{*}{ Mean $=0.42$} & 0.00 & Mean=4996 & 0.37 & Mean=0.87 & 0.13 & EM \\
\hline & $-1.29^{* * *}$ & & $1.91^{* * *}$ & & -0.18 & EU \\
\hline & -0.52 & & 0.63 & & -0.21 & WP \\
\hline WP & 0.39 & $\mathrm{WP}$ & $-0.76^{* * *}$ & WP & -0.11 & $\mathrm{AF}$ \\
\hline $\mathrm{n}=21$ & 0.23 & $\mathrm{n}=19$ & -0.37 & $\mathrm{n}=19$ & -0.06 & $\mathrm{AM}$ \\
\hline \multirow[t]{3}{*}{ Mean=3.18 } & 0.52 & Mean $=4070$ & -0.26 & Mean $=0.83$ & 0.34 & EM \\
\hline & $-0.77^{* *}$ & & $1.28^{* * *}$ & & 0.03 & EU \\
\hline & 0.52 & & -0.63 & & 0.21 & SEA \\
\hline
\end{tabular}

One-way ANOVA, Bonferroni was conducted to explore the mean difference between the six WHO regions. WHO region abbreviations: AF, Africa; AM, Americas; EM, EM, Eastern Mediterranean; EU, Europe; SEA, South-East Asia; WP, Western Pacific.

Mean difference comparison results are reported. Significance of differences $* p<0.05, * * p<0.01, * * * p<0.001$

Data sources: Melanoma of skin incidence rate is from the International Agency for Research on Cancer, WHO agent in cancer research; UVR, expressed as the average daily ambient ultraviolet radiation level (in $\mathrm{J} / \mathrm{m}^{2}$ ) is from the World Health Organization. 
Table 3 Worldwide relationships between melanoma (C43) incidence and Europeans \% in nonparametric (Spearman "rho"), partial correlations and Stepwise multiple linear regression analyses

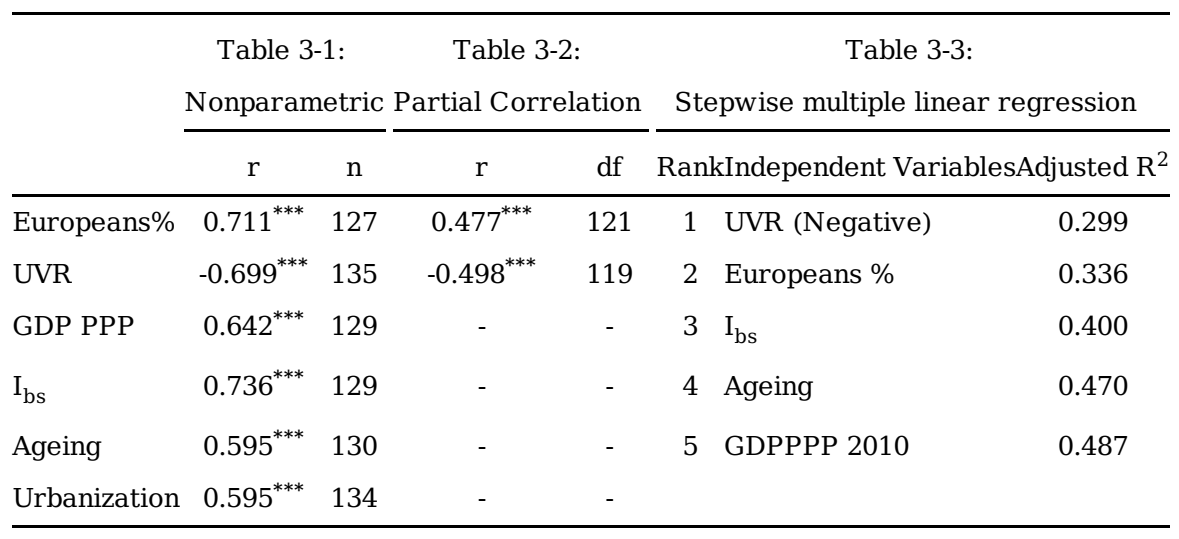

Correlation significance level: ${ }^{* * *} \mathrm{p}<0.001,{ }^{* *} \mathrm{p}<0.01,{ }^{*} \mathrm{p}<0.05$

- Control variable

Data sources: Europeans \% (percentage of European descendants ) from the corresponding government statistics or various publications; Melanoma of skin incidence rate from the International Agency for Research on Cancer, WHO agent in cancer research; UVR, expressed as the average daily ambient ultraviolet radiation level (in $\mathrm{J} / \mathrm{m}^{2}$ ) \& ageing (life $\mathrm{e}_{60}$ ) from the World Health Organization; GDP PPP \& Urbanization from the World Bank; $\mathrm{I}_{\mathrm{bs}}$ from the previous publication (Budnik \& Henneberg 2017).

Table 4 Relationships between depigmentation level and melanoma (C43) incidence within WHO Europe Region in nonparametric (Spearman "rho"), partial correlations and Stepwise multiple linear regression analyses 


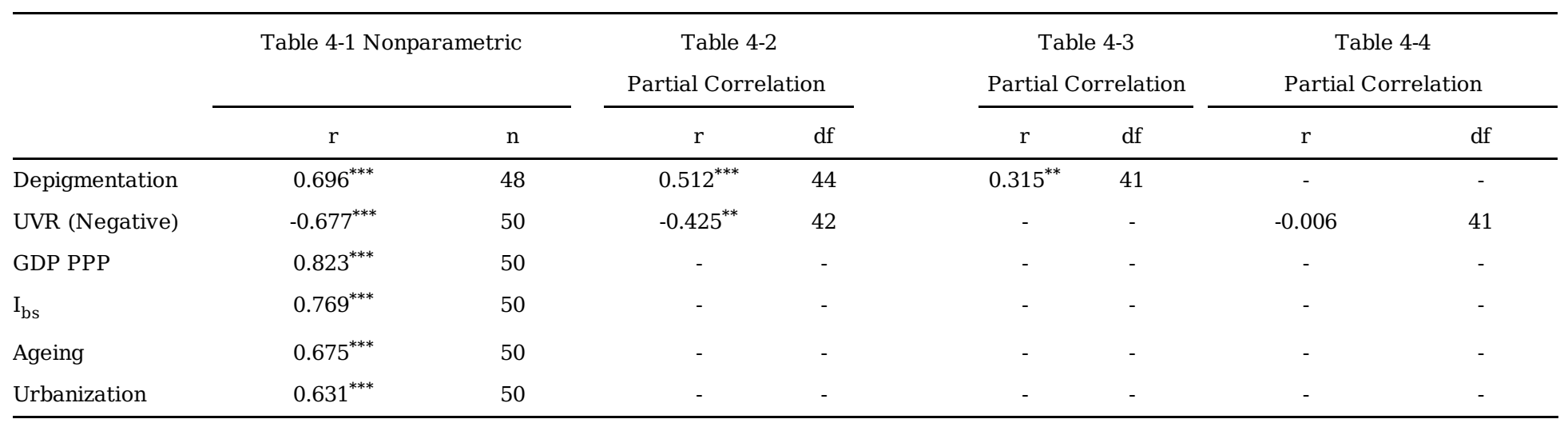

- Variable kept statistically constant.

Data sources: Melanoma of skin incidence rate from the International Agency for Research on Cancer, WHO agent in cancer research; Pigmentation from the previous publication (Carleton 1939); UVR, expressed as the average daily ambient ultraviolet radiation level (in $/ \mathrm{m}^{2}$ ) \& ageing (life e60) from the World Health Organization; GDP PPP \& Urbanization from the World Bank; $\mathrm{I}_{\mathrm{bs}}$ from the previous publication (Budnik \& Henneberg 2017).

Table 4-5: Stepwise multiple linear regression $(n=50)$

\begin{tabular}{|c|c|c|c|c|c|c|c|c|}
\hline \multicolumn{2}{|c|}{ Rank Independent Variables } & \multirow{2}{*}{$\begin{array}{l}\text { Adjusted R }{ }^{2} \\
0.657\end{array}$} & \multicolumn{2}{|c|}{ Rank Independent Variables } & \multirow{2}{*}{$\begin{array}{l}\text { Adjusted R }{ }^{2} \\
0.642\end{array}$} & \multirow{2}{*}{$\begin{array}{l}\text { Rank } \\
1\end{array}$} & \multirow{2}{*}{$\begin{array}{l}\text { Independent Variables } \\
\text { GDP PPP }\end{array}$} & \multirow{2}{*}{$\begin{array}{l}\text { Adjusted } \mathrm{R}^{2} \\
0.657\end{array}$} \\
\hline 1 & GDP PPP & & 1 & GDP PPP & & & & \\
\hline 2 & UVR exposure (Negative) & 0.711 & 2 & Depigmentation & 0.720 & 2 & Depigmentation & 0.732 \\
\hline 3 & $\mathrm{I}_{\mathrm{bs}}$ & 0.742 & 3 & $\mathrm{I}_{\mathrm{bs}}$ & 0.768 & 3 & $\mathrm{I}_{\mathrm{bs}}$ & 0.771 \\
\hline 4 & Ageing & Insignificant & 4 & Ageing & Insignificant & 4 & Ageing & Insignificant \\
\hline 5 & Urbanization & Insignificant & 5 & Urbanization & Insignificant & 5 & Urbanization & Insignificant \\
\hline 6 & Depigmentation & Non-predictor & 6 & UVR exposure & Non-predictor & 6 & UVR exposure & Insignificant \\
\hline
\end{tabular}

Stepwise multiple linear regression modelling was reported. Contribution of variables is listed in order of how much they contribute to Melanoma of skin incidence.

Data sources: Melanoma of skin incidence rate from the International Agency for Research on Cancer, WHO agent in cancer research; Europeans $\%$ (percentage of European diaspora/descendants) from the corresponding government statistics or various publications; Pigmentation from the previous publication (Coon1939); UVR, expressed as the average daily ambient ultraviolet radiation level (in J/ $\mathrm{m}^{2}$ ) \& ageing (life e60) from the WHO; GDP PPP \& Urbanization from the World Bank; Ibs from the previous publication (Budnik \& Henneberg 2017).

\section{Figures}


Figure 1 Relationship between solar ultraviolet radiation exposure and melanoma of skin cancer incidence rate worldwide

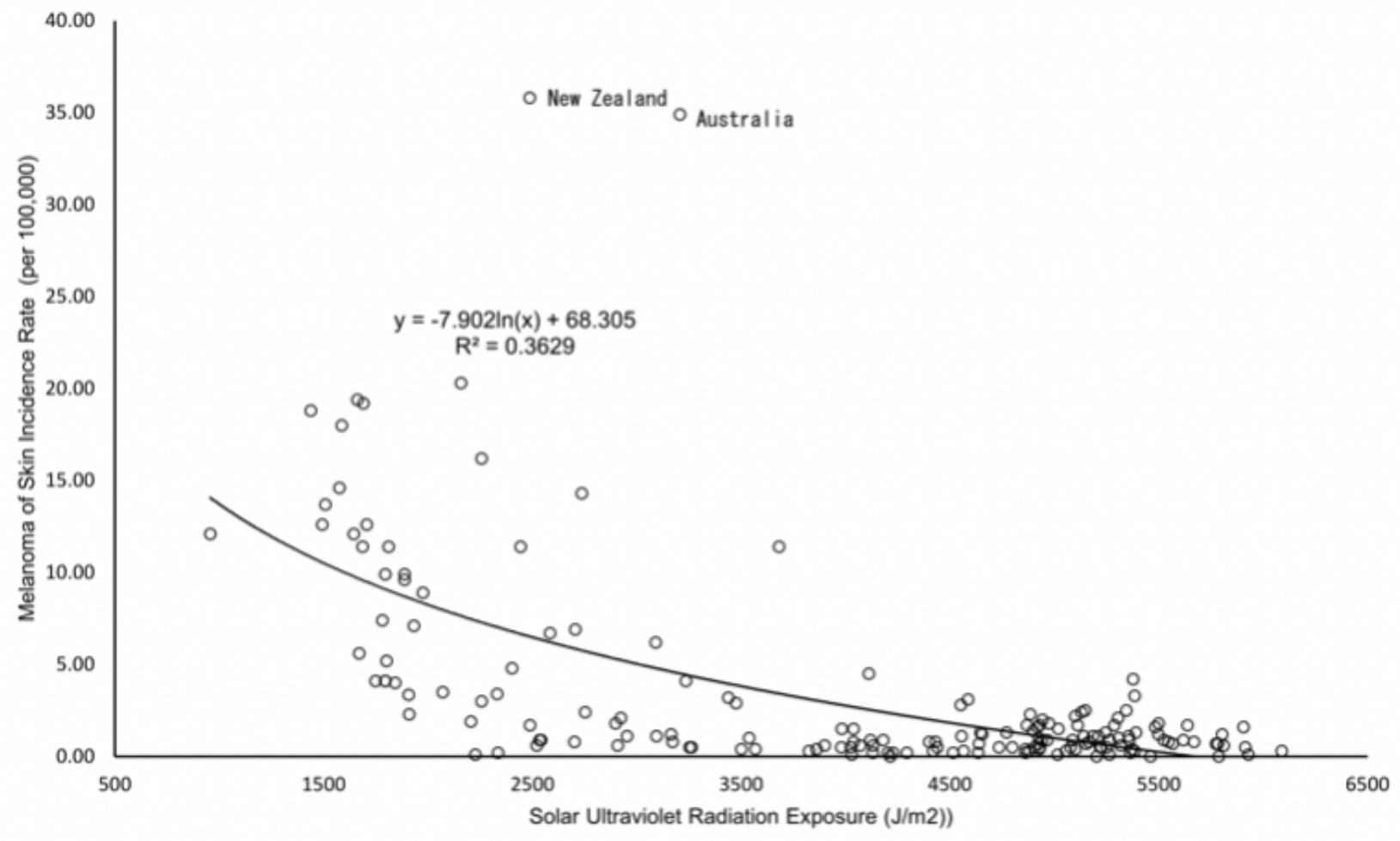

\section{Figure 1}

Relationship between low solar ultraviolet radiation exposure and malignant melanoma of skin (C43) incidence rate worldwide. Legends: Data sources: Melanoma of skin incidence rate from the International Agency for Research on Cancer, WHO agent in cancer research; UVR, expressed as the average daily ambient ultraviolet radiation level (in $\mathrm{J} / \mathrm{m} 2$ ) 
Figure 2: Relationships between melanoma incidence and percentage of EU population and ultraviolet radiation

Figure 2-1: Relationship betweem ultraviolet radiation and melanoma incidence

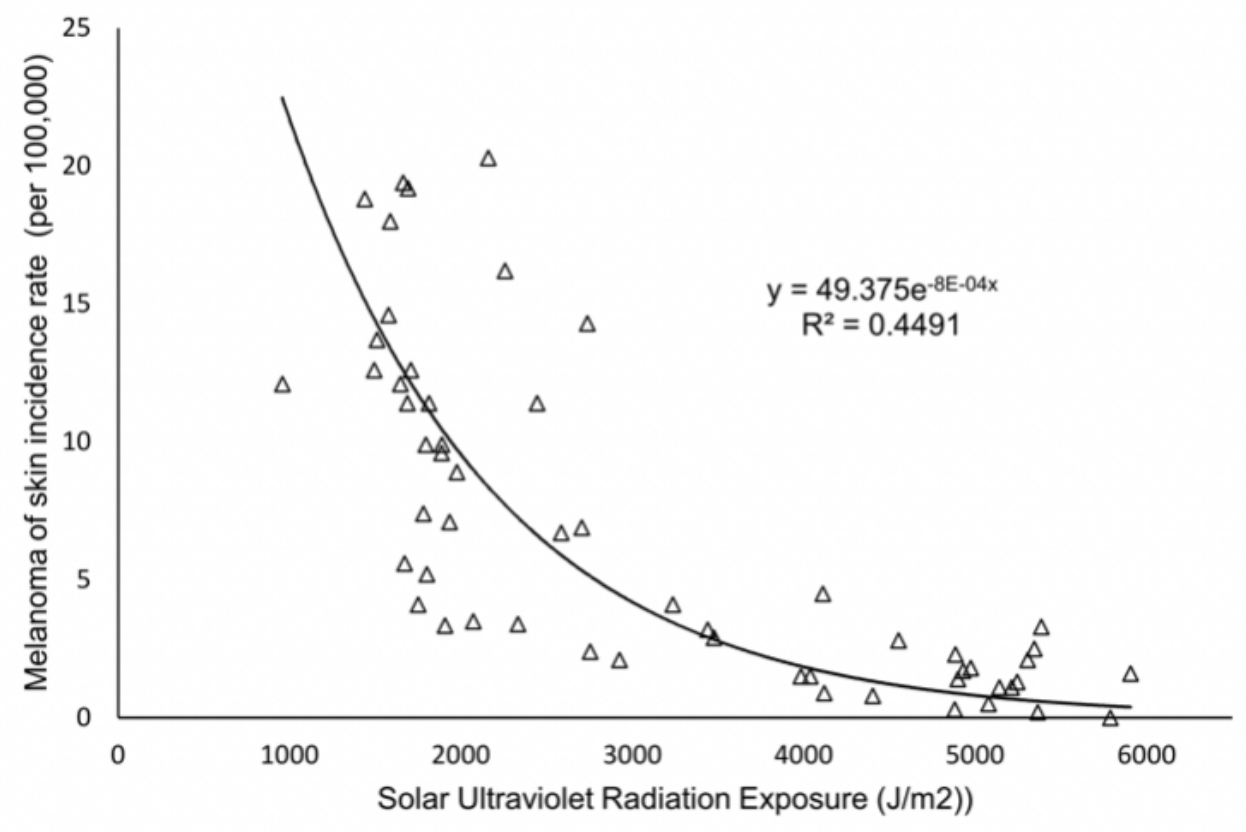

Figure 2-2: Relationship betweem country specific percentage of EU population and melanoma incidence

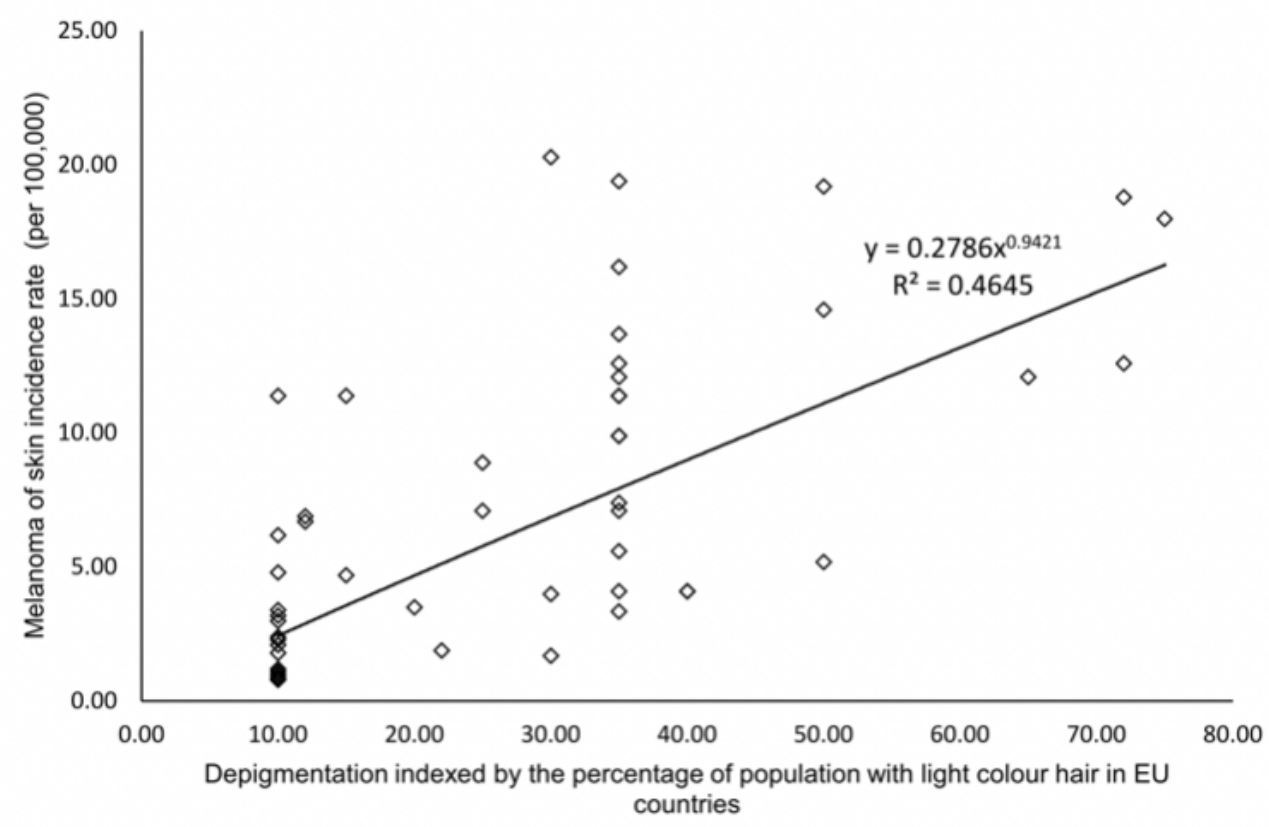

\section{Figure 2}

Population-level relationship between country specific percentage of European descendants and malignant melanoma of skin cancer (C43) incidence rate. Legends: Data sources: Melanoma of skin incidence rate from the International Agency for Research on Cancer, WHO agent in cancer research; Europeans \% (percentage of European diaspora/descendants) from the corresponding government 
statistics or various publications; UVR, expressed as the average daily ambient ultraviolet radiation level (in $\mathrm{J} / \mathrm{m} 2$ ) \& ageing (life e60) from the WHO.

Figure 3: Relationships between melanoma incidence and ultraviolet radiation and depigmentation respectively

Figure 3-1: Relationship betweem ultraviolet radiation and melanoma incidence

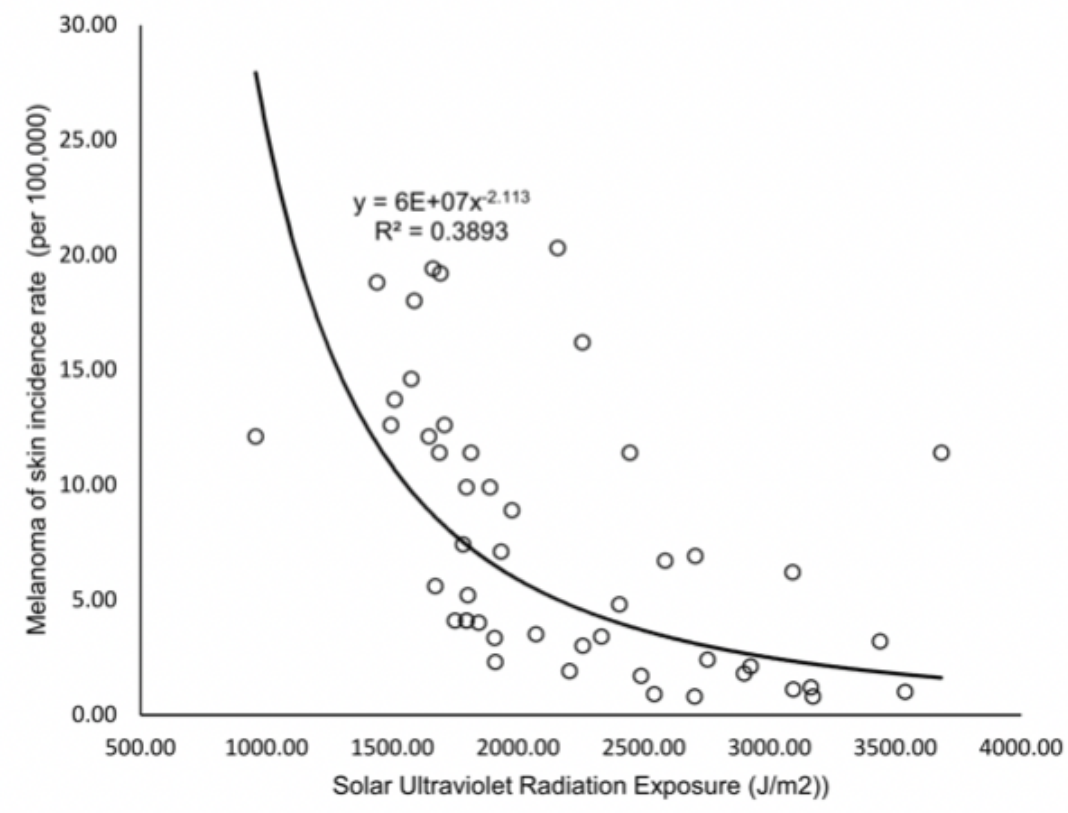

Figure 3-1: Relationship betweem depigmentation and melanoma incidence

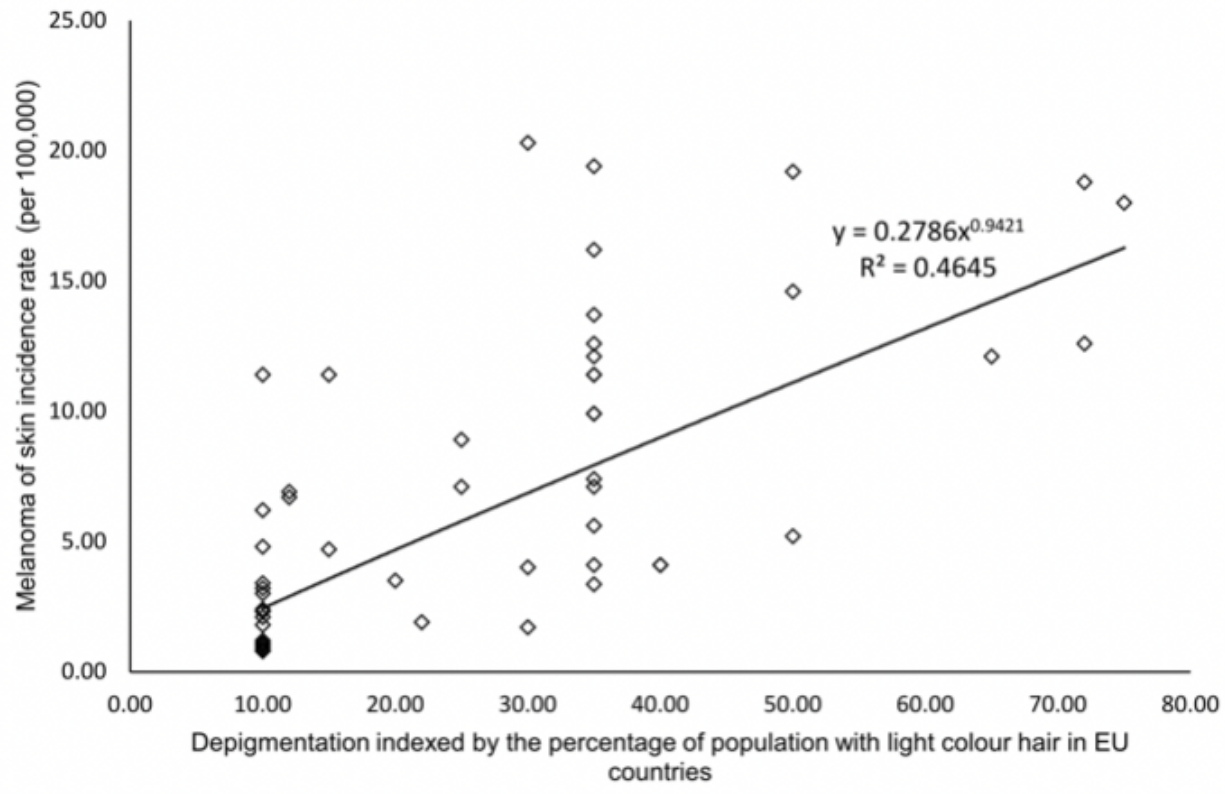

\section{Figure 3}

Relationship between melanoma of skin (C43) incidence and depigmentation level respectively. Legends: Data sources: Melanoma of skin incidence rate from the International Agency for Research on Cancer, 
WHO agent in cancer research; Pigmentation from the previous publication (Carleton 1939); UVR, expressed as the average daily ambient ultraviolet radiation level (in $\mathrm{J} / \mathrm{m} 2$ ). 